\title{
Conhecimento e margens: uma relaÇão dialética na educação ESPECIAL
}

\author{
Juliane Ap. de Paula Perez CAMPOS ${ }^{1}$
}

Caroline Veloso da SILVA ${ }^{2}$

BAPTISTA, C. R.; JESUS, D. M. de (ORGS). Conhecimento e margens - A ção pedagógica e pesquisa em educação especial. Porto Alegre: Mediação, 2009.

Que os temas inclusão e educação especial têm conquistado um espaço importante nas discussões sobre a educação, e com isso al cançado um lugar de destaque, é algo que não se pode negar. Entretanto, ainda há muito a ser feito diante da realidade educacional do Brasil, cujos alunos ditos "normais" não estão total mente incluídos, quanto mais os alunos com deficiência.

Devemos considerar, portanto, que ainda existe uma relação dialética que permeia esse tema, que são justamente o conhecimento e as margens. Sucintamente, é pensar sobre o que conhecemos e o que acontece de fato. É justamente essa discussão que o livro organizado por Claudio Roberto Baptista e Denise Meyrelles de Jesus traz ao leitor.

Fruto de um encontro de instituições e profissionais preocupados com a educação especial no âmbito da formação docente e pesquisa, esse livro traz dez artigos, que tratam de alguns dos princi pais temas da área, como a formação docente, o paradoxo entre a teoria e a prática do processo de ensino/ aprendizagem, a aplicabilidade das tecnologias assistivas, as arbitrariedades no diagnóstico do indivíduo que necessita de educação especial, o autoreconhecimento do sujeito com deficiência perante a sociedade, a busca de conhecimento em educação especial por meio das pesquisas que estão sendo realizadas na atualidade.

No âmbito do diagnóstico de indivíduos com deficiência, Carla Vasquez traz a tona um tema de grande relevância, que é a inclusão de alunos com autismo e psicose infantil. A autora mostra que a falta de conhecimento sobre a deficiência leva à exclusão desse aluno, o que ela nomeia de "construções em torno de um vazio". N esse mesmo contexto, Hiran Pinel nos direciona à

\footnotetext{
${ }^{1}$ Doutora em Educação Especial. Docente do curso de Licenciatura em Educação Especial/ UFSCar julianepaula@hotmail.com

${ }^{2}$ Graduanda do curso de Licenciatura em Letras-Espanhol/ UFSCar - carol_veloso21@yahoo.com.br
} 
reflexão sobre o enrijecimento que um diagnóstico pode provocar, frente às questões sociais e de desenvolvimento do indivíduo com deficiência.

Sobre formação docente e práticas pedagógicas, Rita Magalhães discute a relevância deste processo para a inclusão de alunos com deficiência a partir da relação humana, que compreende o conhecimento de "si e do outro". Lúcia Reily destaca a importância da arte no contexto da educação especial por meio de relatos de uma proposta de trabalho com um grupo de crianças surdas em idade escolar. No que concerne à educação infantil, Sônia Lopes mostra a necessidade da formação docente para essa etapa da vida escolar mostrando sua relevância para o processo de inclusão. Leila Nunes e Maria Cristina Danelon evidenciam o uso de tecnologia assistiva no processo de ensino/ aprendizagem, para proporcionar ao aluno com deficiência um aprendizado satisfatório. Nesse ínterim, somos levados à conclusão de que o professor é a peça chave para que esse aprendizado se concretize, e é justamente essa a questão que as pesquisas destacam.

Nos textos de Reginaldo Sobrinho e Ivone Oliveira, percebemos a necessidade de compreendermos o mundo e o modo como são vistos os sujeitos desse mundo. É pensar que os sujeitos são constituídos historicamente, e essa definição implica em vislumbrar que o homem tem uma concepção de si, do outro e da sociedade a qual está inserido. Portanto, os autores discutem como essa concepção da pessoa com deficiência sobre si, implica na constituição de sua vida.

Para finalizar, Anna Maria Padilha, José Geraldo Bueno e Eduardo Manzini nos trazem o conhecimento sobre os caminhos da pesquisa em educação especial no Brasil. Empiricamente, Padilha aborda questões que envolvem a escolha da metodologia de pesquisa em educação especial. Bueno faz um bal anço da produção discente que pesquisa nessa mesma área, porém com uma abordagem sociológica, e tendo como principal referência Pierre Bourdieu. N este texto, o autor buscou ressaltar a contribuição que essa vertente pode oferecer, em interface com a educação especial. Manzini aborda em seu texto a importância da valorização da entrevista como metodologia de pesquisa em educação especial, e destaca a relevância da qualificação do entrevistador, visto que trata-se de interação direta com o sujeito da pesquisa.

As discussões levantadas nestes textos proporcionam ao leitor uma visão crítica do que se discute em educação especial atualmente e leva a uma reflexão sobre os avanços nas pesquisas, e sobre a questão da formação docente, cujo trabalho muitas vezes é solitário, ainda às margens do conhecimento. 